\title{
ANNOUNCEMENT
}

\section{THE OSGOOD PRIZE}

Richard G. Osgood was a promising young paleontologist whose career was cut short. After his death in June of 1981, his former advisor Dr. K. E. Caster, of the University of Cincinnati, made the first contribution to the Osgood Publications Fund of the Paleontological Research Institution (PRI). It was hoped that as this fund grew, earnings could be used to recognize and provide monetary assistance to authors of outstanding monographs accepted for publication by the PRI. Since that time, continued contributions and accumulated earnings have increased the principal balance of the fund to over $\$ 24,000$. Shortly after the fund was initiated, the trustees of the PRI appointed a committee to formulate guidelines for awards and other disbursements from the Fund. From their deliberations came the idea to use half the interest generated by the Fund for such disbursements, the other half to be reinvested to principal. In 1986, the trustees decided that the fund had grown large enough that $\$ 500$ could be set aside each year as the Osgood Prize, to recognize the author or authors of a fundamental contribution in the field of paleontology. It was also decided that the remaining funds available for disbursement could be used to help "needy" authors of manuscripts accepted for publication by the PRI defray their share of publication costs.

About two years ago, both reviewers of a manuscript submitted to the PRI for publication recommended it for the Osgood Prize. Subsequently, a committee appointed to study the matter unanimously seconded those recommendations, and on May 6, 1989, the trustees of the PRI voted unanimously to award the first Osgood Prize to Edward M. Snyder, author of the manuscript, "Revised Taxonomic Procedures and Paleoecological Applications for some North American Mississippian Fenestellidae and Polyporidae (Bryozoa)," which has been accepted for publication in Palaeontographica Americana. The Paleontological Society has invited a representative of the PRI to present the Osgood Prize to Dr. Snyder at its Annual Luncheon, which was held during the Annual Meetings of the Geological Society of America and associated societies, in St. Louis, Missouri, during the week of November 6, 1989.

Peter R. Hoover, Director

The Paleontological Research Institution 1259 Trumansbury Road

Ithaca, NY 14850-1398

\section{ANNOUNCEMENT}

\section{STUDENT GRANTS}

The Paleontological Society is pleased to announce receipt of a second generous monetary contribution from the Margaret Cullinan Wray Charitable Lead Annuity Trust, which will be disbursed on a competitive basis to graduate and postdoctoral student members of the Society in the form of 20 individual $\$ 500$ grants. Applicants who received grants in 1989 are again encouraged to apply, but priority will be given to applicants who have not received grants before. Application forms and instructions for filing them will shortly be available from department heads at graduate-degree-granting institutions in the United States and Canada, or may be obtained directly by writing to the Society's selection committee chairman:

Walter C. Sweet

Department of Geology \& Mineralogy

The Ohio State University

125 South Oval Mall

Columbus, Ohio 43210 